\title{
Estimates of magnetotail reconnection rate based on IMAGE FUV and EISCAT measurements
}

\author{
N. Østgaard ${ }^{1}$, J. Moen ${ }^{2,3}$, S. B. Mende ${ }^{1}$, H. U. Frey ${ }^{1}$, T. J. Immel ${ }^{1}$, P. Gallop ${ }^{4}$, K. Oksavik ${ }^{2}$, and M. Fujimoto ${ }^{5}$ \\ ${ }^{1}$ Space Sciences Laboratory, University of California, Berkeley, California, USA \\ ${ }^{2}$ Department of Physics, University of Oslo, Norway \\ ${ }^{3}$ University Centre on Svalbard, Longyearbyen, Norway \\ ${ }^{4}$ Rutherford Appleton Laboratory, Oxfordshire, UK \\ ${ }^{5}$ Department of Earth and Planetary Sciences, Tokyo Institute of Technology, Japan
}

Received: 16 September 2003 - Revised: 15 March 2004 - Accepted: 30 March 2004 - Published: 31 January 2005

Part of Special Issue "Eleventh International EISCAT Workshop"

\begin{abstract}
Dayside merging between the interplanetary and terrestrial magnetic fields couples the solar wind electric field to the Earth's magnetosphere, increases the magnetospheric convection and results in efficient transport of solar wind energy into the magnetosphere. Subsequent reconnection of the lobe magnetic field in the magnetotail transports energy into the closed magnetic field region. Combining global imaging and ground-based radar measurements, we estimate the reconnection rate in the magnetotail during two days of an EISCAT campaign in November-December 2000. Global images from the IMAGE FUV system guide us to identify ionospheric signatures of the open-closed field line boundary observed by the two EISCAT radars in Troms $\varnothing$ (VHF) and on Svalbard (ESR). Continuous radar and optical monitoring of the open-closed field line boundary is used to determine the location, orientation and velocity of the openclosed boundary and the ion flow velocity perpendicular to this boundary. The magnetotail reconnection electric field is found to be a bursty process that oscillates between $0 \mathrm{mV} / \mathrm{m}$ and $1 \mathrm{mV} / \mathrm{m}$ with $\sim 10-15 \mathrm{~min}$ periods. These ULF oscillations are mainly due to the motion of the open-closed boundary. In situ measurements earthward of the reconnection site in the magnetotail by Geotail show similar oscillations in the duskward electric field. We also find that bursts of increased magnetotail reconnection do not necessarily have any associated auroral signatures. Finally, we find that the reconnection rate correlates poorly with the solar wind electric field. This indicates that the magnetotail reconnection is not directly driven, but is an internal magnetospheric process. Estimates of a coupling efficiency between the solar wind electric field and magnetotail reconnection only seem to be relevant as averages over long time intervals. The oscillation mode at $1 \mathrm{mHz}$ corresponds to the internal cavity mode with
\end{abstract}

Correspondence to: N. Østgaard

(nikost@ssl.berkeley.edu) additional lower frequencies, 0.5 and $0.8 \mathrm{mHz}$, that might be modulated by solar wind pressure variations.

Key words. Magnetospheric physics (magnetotail; electric fields; magnetosphere - ionosphere interaction; solar wind magnetosphere interaction). Space plasma physics (magnetic reconnection)

\section{Introduction}

A fundamental element of the open magnetosphere model first suggested by Dungey (1961) is that dayside merging and subsequent magnetotail reconnection transfer solar wind plasma and energy to the magnetospheric-ionospheric system. Dayside reconnection generates open magnetic flux whereas the magnetotail cross-tail reconnection destroys open flux by converting it back to closed flux. The cycle of accumulation and loss of open flux is also related to the magnetospheric behavior during substorms. In the Dungey cycle this circulation of flux was assumed to be a steady-state phenomenon, with the rates of merging on the dayside and reconnection in the tail balancing each other. However, as suggested by Russell (1972), the two processes may be viewed as two separate time-dependent processes. This means that while dayside merging is thought to be controlled by the interplanetary magnetic field (IMF), magnetotail reconnection may not have a similar strong IMF dependence.

Reconnection may occur at two different locations in the magnetotail. The first type of reconnection is associated with the formation of the far X-line and defines the last closed field line of the magnetosphere. A second type, which is more controversial, is associated with the formation of the near Earth neutral line (NENL). We do not know if this type of reconnection is controlled by the solar wind, IMF, or is entirely controlled by some internal magnetospheric instabil- 
ities or some combination thereof. However, if the reconnection rate at the NENL location exceeds that at the far X-line location, the open-closed boundary will approach the NENL and its ionospheric footpoint will move equatorward. At this moment the last closed field line will thread both the NENL and the far X-line. The newly formed NENL will then become the new far X-line, which will propagate tailward. This tailward motion is associated with a poleward motion of the open-closed boundary in the ionosphere.

As the far X-line or the NENL defines the boundary between open-closed field lines it has been shown theoretically that the plasma flow through the open-closed boundary in the ionosphere can be utilized to estimate the reconnection electric field in the magnetotail (Vasyliunas, 1984).

Crucial for this method is, however, how accurate one is able to determine the open-closed boundary. According to Lockwood (1997) the open-closed boundary can be identified from the diffuse electron precipitation from the plasma sheet boundary layer or from the equatorward drifting arcs which form just equatorward of the open-closed boundary (Fujii et al., 1994; Hoffman et al., 1994) and are embedded in this diffuse precipitation. These arcs are also associated with intense electric fields (Pedersen et al., 1985) and thought to be Alfvén wave signatures of processes near or at the reconnection line (Hesse et al., 1999; Yamade et al., 2000). The accuracy by which one can determine the open-closed boundary is therefore highly dependent on the sensitivity and spatial resolution of the instruments that are used. Lockwood (1997) suggested that the open-closed boundary is roughly $200 \mathrm{~km}$ poleward of where an imager from space will place the open-closed boundary.

A few studies have reported quantitative results of the reconnection electric field in the magnetotail and have used different ways to identify the open-closed boundary.

de la Beaujardiére et al. (1991) used incoherent scatter radar data from Søndre Strømfjord to obtain the plasma flow and to locate the open-closed boundary. The latter was determined from gradients of the density in the ionospheric Eregion layer as precipitating energetic electrons enhance the density in the auroral oval relative to the polar cap. They reported ionospheric projections of the reconnection electric field to be $20-40 \mathrm{mV} / \mathrm{m}$.

A similar method was used by Blanchard et al. (1996, 1997). In addition to the gradient of E-region electron density they used the $6300 \AA$ emissions from an all-sky camera to define the open-closed boundary. They found the ionospheric projection of the reconnection electric field to vary between $0-60 \mathrm{mV} / \mathrm{m}$. Compared to the solar wind electric field they found an average coupling efficiency of 0.1 and a maximum correlation when introducing a 70-min timelag to the solar wind data. They also found that the reconnection rate increased significantly during the expansion phase of substorms.

Ober et al. (2001) used in-situ measurements to estimate the reconnection electric field just as the Polar satellite traversed the open-closed boundary during the expansion phase of a substorm. Combined particle, electric field and mag- netic field measurements were used to determine the ion flow perpendicular to the open-closed boundary, and images from the VIS Earth camera $(130.4 \mathrm{~nm})$ were used to determine the boundary velocity. Although no temporal information can be extracted from such a boundary crossing, their result represents an important in-situ measurement of the reconnection electric field. They found the ionospheric projection of the reconnection electric field to be $20-70 \mathrm{mV} / \mathrm{m}$.

In this paper we have used images from IMAGE FUV and data from the EISCAT VHF radar in Troms $\varnothing$ (VHF) and the EISCAT Svalbard radar (ESR) to estimate the reconnection rate during two time intervals of an EISCAT campaign in November-December 2000. On 28 November 2000, the expansion and recovery phase of a relatively strong substorm was observed by IMAGE and the Troms $\varnothing$ VHF radar. The data from 7 December 2000 were obtained during a quieter geomagnetic time, although a clear auroral intensification, which may be classified as a weak substorm, was observed by IMAGE and the EISCAT Svalbard radar. Section 2 describes the instruments and data quality, Section 3 gives an overview of the theoretical framework developed by Vasyliunas (1984) as well as the geometry of the observations. The events are presented in Sections 4 and 5, while the discussion and conclusions are presented in Sections 6 and 7.

\section{Instrumentation and data processing}

The IMAGE FUV instrumentation consists of two different cameras, the wide band imaging camera (WIC) and the spectrographic imager (SI). The SI provides separate measurements of the O line at $135.6 \mathrm{~nm}$ (SI13) and the Dopplershifted Lyman $\alpha$ emission at $121.8 \mathrm{~nm}$ (SI12), the latter designed to measure auroral emissions from proton precipitation. For boundary determination and auroral intensity we use measurements from the WIC camera, as this camera has the highest sensitivity and spatial resolution. The WIC camera measures FUV emissions in the $140-180 \mathrm{~nm}$ wavelength range. These are $\mathrm{N}_{2}$ emissions in the Lyman-BirgeHopfield band and a few $\mathrm{N}$ emission lines. These emissions are all prompt emissions which result in highly detailed auroral images. The sensitivity of the WIC camera, meaning the auroral intensity needed for the aurora to be distinguished from noise, after background subtraction, is about 100 counts/pixel or $\sim 250 \mathrm{R}$. The spatial resolution depends on the altitude of the spacecraft, but is $\sim 100 \mathrm{~km}$ at apogee ( 8 $R_{E}$ geocentric distance). For a more complete description of the FUV imaging system, see Mende et al. (2000) and Frey et al. (2003).

The two incoherent-scatter radars in Troms $\varnothing$ (VHF) and on Svalbard (ESR) provide measurements of the electron density, electron and ion temperature and the ion flow velocity along the radar beam. This study uses the electron temperature for open-closed boundary determination and the ion flow velocity across this boundary to estimate the reconnection electric field. 
Figure 1 shows the radar beam directions for the two days of observations, when mapped down along the magnetic field to $100 \mathrm{~km}$ altitude. One of the VHF beams (Troms $\varnothing$ ) was directed approximately along the magnetic meridian (west beam), while the other beam was directed towards geographic north (north beam). The radar sampled data in 19 range intervals at altitudes from $230 \mathrm{~km}$ to $1052 \mathrm{~km}$ and the integration time used in the data analysis is 1 minute. As explained in Section 3.1, only data sampled above $300 \mathrm{~km}$ are used, which corresponds to intervals 5-19. The spatial resolution in the beam direction, when mapped down to $100 \mathrm{~km}$ altitude, ranges from $\sim 30 \mathrm{~km}$ (interval 5) to $\sim 140 \mathrm{~km}$ (interval 19). The EISCAT Svalbard radar was directed at $135^{\circ}$ azimuth from geographic north with a $30^{\circ}$ elevation and sampled data at altitudes from $106 \mathrm{~km}$ to $596 \mathrm{~km}$. These data are analyzed with a $26 \mathrm{~s}$ integration time in 16 spatial intervals, where only data above gate $9(>300 \mathrm{~km})$ can be used. The spatial resolution for the latter (at $100 \mathrm{~km}$ ) ranges from $\sim 30 \mathrm{~km}$ (gate 9) to $\sim 60 \mathrm{~km}$.

\section{Approach}

\subsection{Method to calculate the reconnection rate}

The method to calculate the reconnection electric field from the ion flow across the open-closed boundary in the nightside ionosphere is based on the theoretical approach presented by Vasyliunas (1984). As sketched in Fig. 2 the Xline in the magnetotail, $C_{m}$, is connected to the ionosphere along the two magnetic field lines, $C_{p}$, to form a closed loop $\left(C_{m}+C_{p}+C_{i}+C_{p}\right)$ along the separatrix, which delineates the area, $A$. If $\mathbf{u}$ is defined as the velocity of the loop, Faraday's law (integral form) applied on this closed loop gives us

$$
\oint(\mathbf{E}+\mathbf{u} \times \mathbf{B}) \cdot d \mathbf{l}=-\frac{d}{d t} \int \mathbf{B} \cdot d \mathbf{A} .
$$

By definition no magnetic field lines cross the separatrix (i.e. the field lines defining the surface of area $A$ ) and Eq. (1) can be written

$$
\int_{C_{m}}(\mathbf{E}+\mathbf{u} \times \mathbf{B}) \cdot d \mathbf{l}+\int_{\text {rest }}(\mathbf{E}+\mathbf{u} \times \mathbf{B}) \cdot d \mathbf{l}=\mathbf{0},
$$

where $r$ est $=C_{p}+C_{i}+C_{p}$. In the first term $(\mathbf{u} \times \mathbf{B}) \cdot d \mathbf{l}=\mathbf{0}$ because $\mathbf{B}$ is either zero or aligned with $C_{m}$. For the rest of the loop the MHD approximation

$\mathbf{E}+\mathbf{v} \times \mathbf{B} \approx \mathbf{0}$

can be applied as long as the dimension of the loop is large compared to a characteristic microscopic scale length of the plasma (e.g. a gyroradius) (Vasyliunas, 1984). This approximation applies for a collisionless plasma and holds even for the segment, $C_{i}$, as long as it is placed above the region where ion-neutral collisions are significant. Using only radar measurements from $>300 \mathrm{~km}$, the ratio of gyrofrequency and the ion-neutral collision frequency is well above 100 (Kelley,

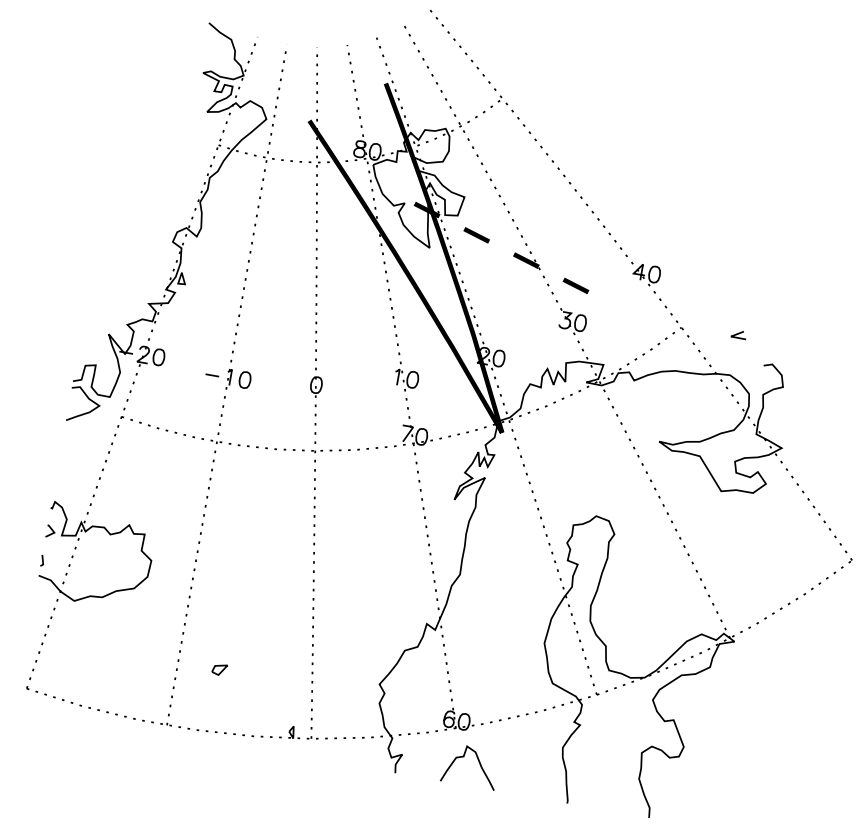

Fig. 1. The beam directions, mapped down to $100 \mathrm{~km}$, for the EISCAT VHF radar in Troms $\emptyset$ (solid lines) on 28 November 2000 and for the EISCAT Svalbard radar (dashed line) on 7 December 2000 shown in geographic coordinates.

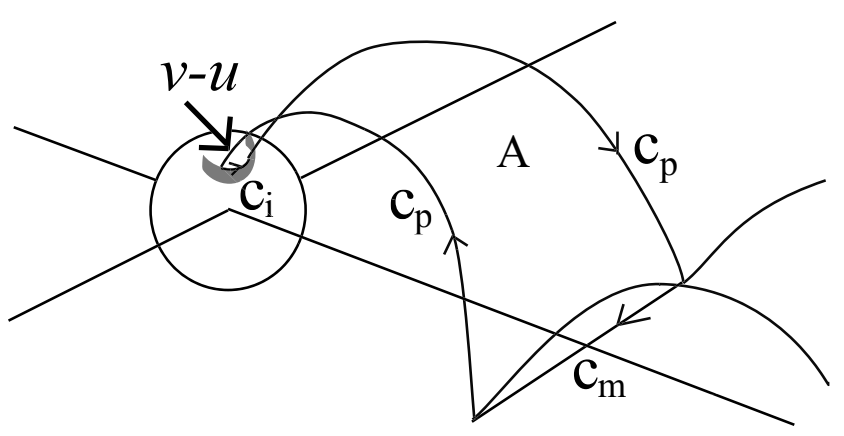

Fig. 2. The geometry for estimating the reconnection rate from ion flow across the open-closed boundary in the nightside ionosphere.

1989, pg. 39). The approximation (Eq. (3) also holds for the two segments $C_{p}$ under one of the following assumptions: The loop is chosen narrow enough so any $E_{\|}$is the same on both segments $C_{p}$ and cancel in the integration. Alternately, $E_{\|} \approx 0$, which is probably a reasonable assumption on the open-closed boundary. Consequently, the MHD approximation should hold for the entire loop. Equation (2) can therefore be written as

$$
\int_{C_{m}} \mathbf{E} \cdot d \mathbf{l} \approx \int_{\text {rest }}([\mathbf{v}-\mathbf{u}] \times \mathbf{B}) \cdot d \mathbf{l}
$$

and because the right term is zero along the two field line segments, $C_{p}$, we finally obtain

$$
\int_{C_{m}} E \cdot d l \approx \int_{C_{i}}([v-u] \cdot B) \cdot d l,
$$


a)
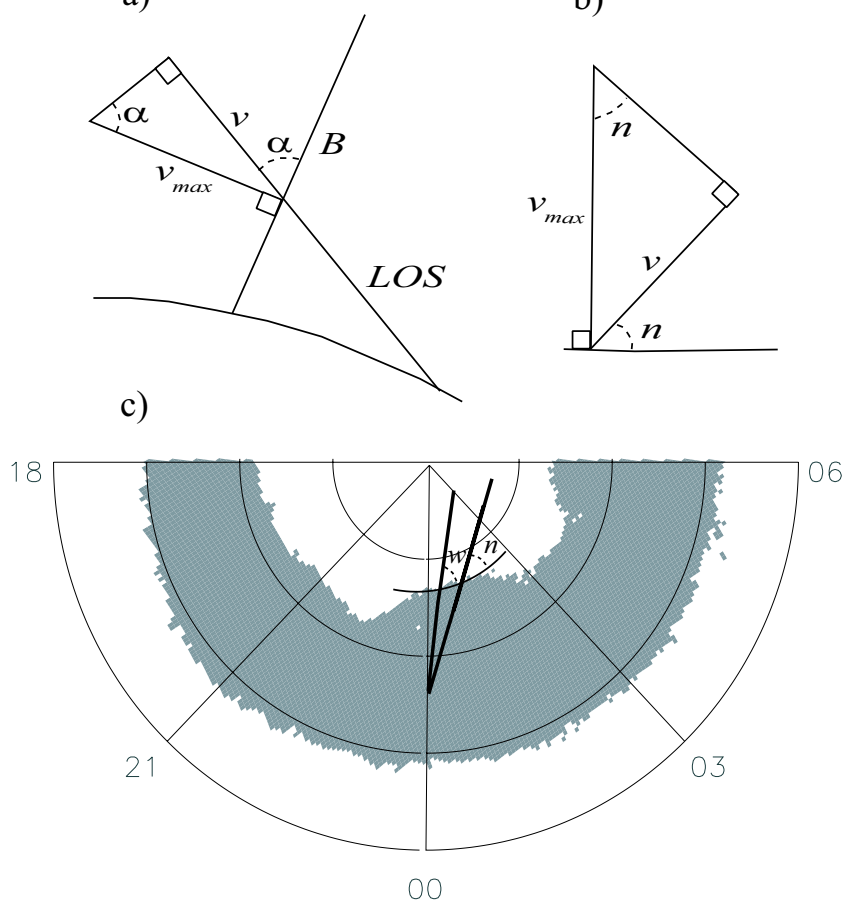

Fig. 3. The angles to consider when estimating the ion flow perpendicular to the magnetic field and the open-closed boundary. (a) $\alpha$ is the angle between the magnetic field line and the measured lineof-sight flow velocity. (b) $n$ is the angle between the open-closed boundary and the north beam of the EISCAT VHF radar. (c) All counts above the noise threshold of FUV WIC (21:59:57 UT) are shown in grey. The straight solid lines show the west and north beam of the EISCAT VHF radar and the curved solid line shows the smooth open-closed boundary along the two line of sights. The angles between the line of sight and the boundary for the west and north beam are denoted $w$ and $n$, respectively. In a) and b) we have indicated the maximum velocity given this geometry.

where $v-u$ is the ionospheric plasma flow velocity perpendicular to the magnetic field in the open-closed boundary reference frame. A positive (equatorward) value of $v-u$ is equivalent to a duskward reconnection electric field in the magnetotail. If $\Delta l_{i}$ is a small segment of $C_{i}$ that we measure in the ionosphere we get

$E_{m} \cdot \Delta l_{m} \approx[v-u]_{i} \cdot B_{i} \cdot \Delta l_{i}=E_{i} \cdot \Delta l_{i}$,

where $\Delta l_{i}$ is much smaller than $\Delta l_{m}$. Assuming that the width of the magnetotail is $40 R_{E}$, the nightside open-closed boundary scales as (Blanchard et al., 1996)

$\frac{\Delta l_{m}}{\Delta l_{i}}=\frac{40 \mathrm{R}_{\mathrm{E}}}{\pi \cdot \cos \lambda \mathrm{R}_{\mathrm{E}}}=\frac{E_{i}}{E_{m}}$,

where $\lambda$ is the magnetic latitude of the open-closed boundary. At $70^{\circ}\left(75^{\circ}, 80^{\circ}\right)$ magnetic latitude $\Delta l_{m}$ is $\sim 40(\sim 50$, $\sim 75)$ times larger than $\Delta l_{i}$ and consequently, $E_{m}$ will be $\sim 40(\sim 50, \sim 75)$ smaller than $E_{i}$.
3.2 How to determine the open-closed boundary location and geometry

In addition to the ion velocity, we need to determine the location, orientation and motion of the open-closed boundary. This information can be obtained from the IMAGE/FUV WIC images.

Figure $3 \mathrm{c}$ shows the image from 28 November 2000 at 21:59:57 UT. After background subtraction a threshold of 100 counts/pixel ( $\sim 250 \mathrm{R})$ was found to be the lowest count rate where the auroral emissions can be distinguished from noise. Along the direction of the radar beams (solid thick lines) the open-closed boundary can be defined as the poleward edge of the aurora, i.e. where the count rates fall below 100 counts/pixel (or $\sim 250$ Rayleigh). From the images we can also define the angles between the radar beams and this boundary, denoted $w$ and $n$, for the west and north beams, respectively (Figs. $3 \mathrm{~b}$ and c). As the EISCAT data only gives us the ion flow along the beam direction, these angles are needed to calculate the ion flow perpendicular to the boundary. A second angle to consider is the angle between the magnetic field and the beam direction, denoted $\alpha$ in Fig. 3a. Under the assumption that the ion velocity is uniform on the scale size that separates the west and north beam $\left(14.7^{\circ}\right.$, which corresponds to a maximum separation less than $350 \mathrm{~km}$ ), we can combine the ion velocities from the west and north beams to calculate the ion velocity perpendicular to the boundary more accurately. In this case the maximum velocity perpendicular to both the boundary and the magnetic field is given by

$v_{\max }=\frac{v}{\sin \alpha}$.

If only one beam direction is available the maximum velocity perpendicular to the boundary and the magnetic field is given by

$v_{\max }=\frac{v}{\sin \alpha \sin n}$.

For the boundary velocity we assume that the boundary motion is along the magnetic meridian. This assumption is partly supported by images, but may not always be true and will be discussed. Consequently, if $u_{m}$ is the boundary velocity we measure along the line of sight the velocity along the magnetic meridian, $u$ (north beam), is given by

$u=u_{m} \sin n$.

For the 28 November event, when two beams can be combined to calculate the ion velocity perpendicular to the boundary, the maximum ion flow velocity and the boundary velocity given by Eqs. (8 and 10) are used as input in Eq. (6). For the 7 December event, when only measurements along one beam were available, Eqs. ( 9 and 10) are used as input in Eq. (6).

To take advantage of the better spatial resolution of the radar data, we will use the open-closed boundary determined from the UV images as guidance to confine the location 


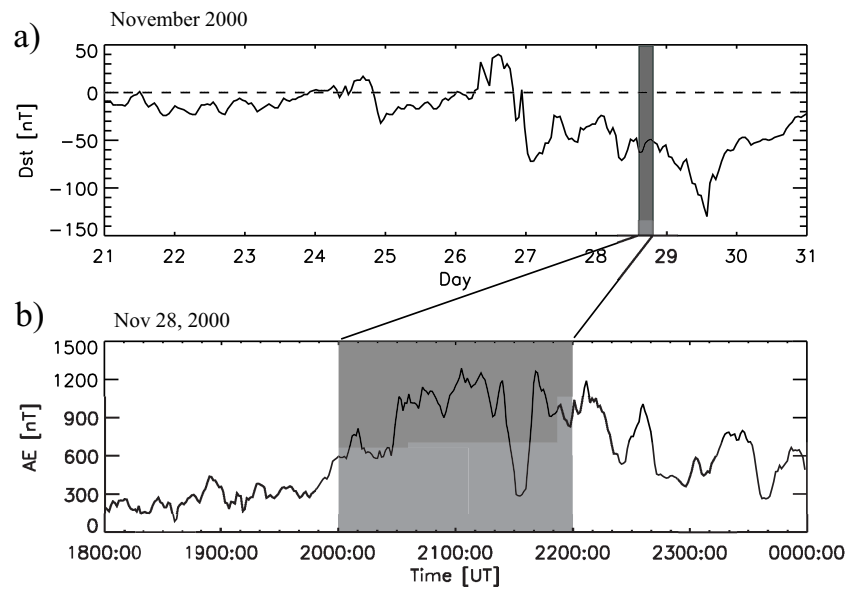

c)

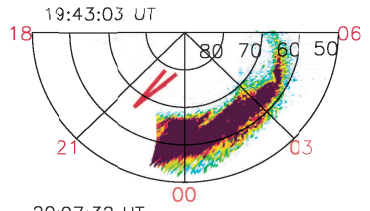

$21: 04: 45$ UT
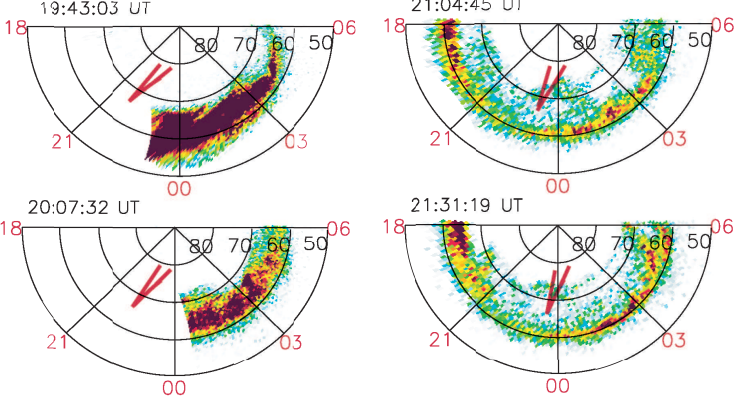

21:31:19 UT

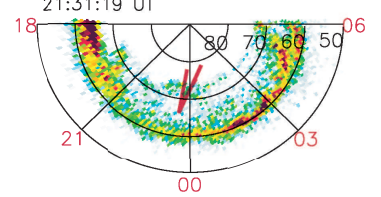

20:30:00 UT

21:59:57 UT
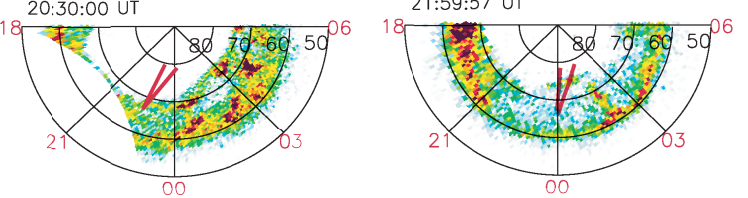

Fig. 4. The Dst (a) and $A E$ (b) indices prior to and during the substorm on 28 November 2000 . The time interval for the analysis is shown by the grey shaded areas. (c) The substorm development as imaged by the SI13 channel $(135.6 \mathrm{~nm})$ of the Spectrographic Imager. Red lines indicate the line of sight of the two beams of the EISCAT VHF radar.

based on the electron temperature measured by the radars. It may be argued that the electron temperature should have been taken from the E-region, where the peak energy deposition associated with diffuse aurora occurs. However, it has been shown theoretically (Kagan et al., 1996) and confirmed by observations (Doe et al., 1997) that Alfvén waves and turbulent electrostatic fields can cause significant heating in the F-region associated with downward field-aligned currents closing at the edge of the polar cap. In the absence of such heating one can argue that the F-region heating associated with precipitation depends on the number flux of precipitating particles, regardless of energy. The number flux of polar rain is usually very low and is easily distinguishable from nightside precipitation on closed field lines. To make sure that we do not misinterpret polar cap F-region heating to be on closed field lines, we will use the electron temperature to define the open-closed boundary when this determination can be confirmed by imaging data. The orientation of the open-closed boundary will be determined from the images.

\section{$4 \quad 28$ November 2000}

In Fig. $4 a$ and $b$ we show the geomagnetic conditions prior to and during the event on 28 November. The grey shaded interval indicates the time interval when both IMAGE and the EISCAT VHF radar measurements were available (20:0022:00 UT). From the provisional Dst index we see that a magnetic storm started late night on 26 November and by 28 November the storm is still in its main phase $\left(D_{s t}\right.$ at $-60 \mathrm{nT})$. As expected, the preliminary quick-look AE index shows rather disturbed conditions ( $300 \mathrm{nT}$ ) even before the substorm occurred. As small parts of the data in some of the WIC images were lost because of a mass memory problem on-board the spacecraft during this time interval, we let a sequence of SI13 images (Fig. 4(c) display the global auroral activity during this substorm. As the IMAGE spacecraft was coming up from perigee the imagers did not capture the onset of the substorm, but the poleward, as well as eastward and westward expansion during the substorm expansion phase, is clearly seen. Figure 5 shows the 1-min VHF data for 28 November 2000, 20:00-22:00 UT. A median filter has been applied to the VHF data to remove unreasonable values. The positions of the gates are mapped down to $100 \mathrm{~km}$ altitude using the Tsyganenko 2001 model (Tsyganenko, 2002) with the IGRF 2000 and solar wind measurements from Wind as input. The poleward boundaries of the auroral emissions and the electron temperature increase should both be good indicators of the open-closed boundary. To take advantage of the better spatial resolution of the radar data, we use the openclosed boundary determined from the images as guidance to confine the location based on the electron temperature measured by the radars. To do this we determine a boundary for 11 different temperatures $(1600-2600 \mathrm{~K}$, in $100 \mathrm{~K}$ steps) and select the one that correlates best with the boundary determined from the images. In Fig. $5 b$ (and d) the boundary determined from the images is shown by squares. In this case the boundary determined from an electron temperature of $2500 \mathrm{~K}$, shown by a solid thin line, gives the best correlation with the image boundary. The discrepancy between the two boundary determinations is in the range of the spatial resolution of the WIC images $\left(100 \mathrm{~km}\right.$ or $\left.\sim 1^{\circ}\right)$. We should also point out that the very high electron density between 21:30 UT and 22:00 UT will have a cooling effect on the electron temperature and we are not able to identify any boundary from the temperature during this interval. To identify the ion flow velocity we use the value in the gate defining the boundary shown by the thin line (Fig. 5d). We also calculate the average of the velocities in the exact gate and in the two gates poleward and equatorward of this. To estimate the velocity of the boundary $(u)$ we use the values shown by the smoothed thick line in order to avoid large steps in velocity due the spatial resolution of the radar measurements. The smoothing is performed by a 5 -min (5 data points) boxcar averaging, meaning that the average of 5 data points represents the center data point.

In Fig. 6a-c the angles and velocities that go into Eq. (8 and 10) to calculate the maximum ion velocity and the boundary 

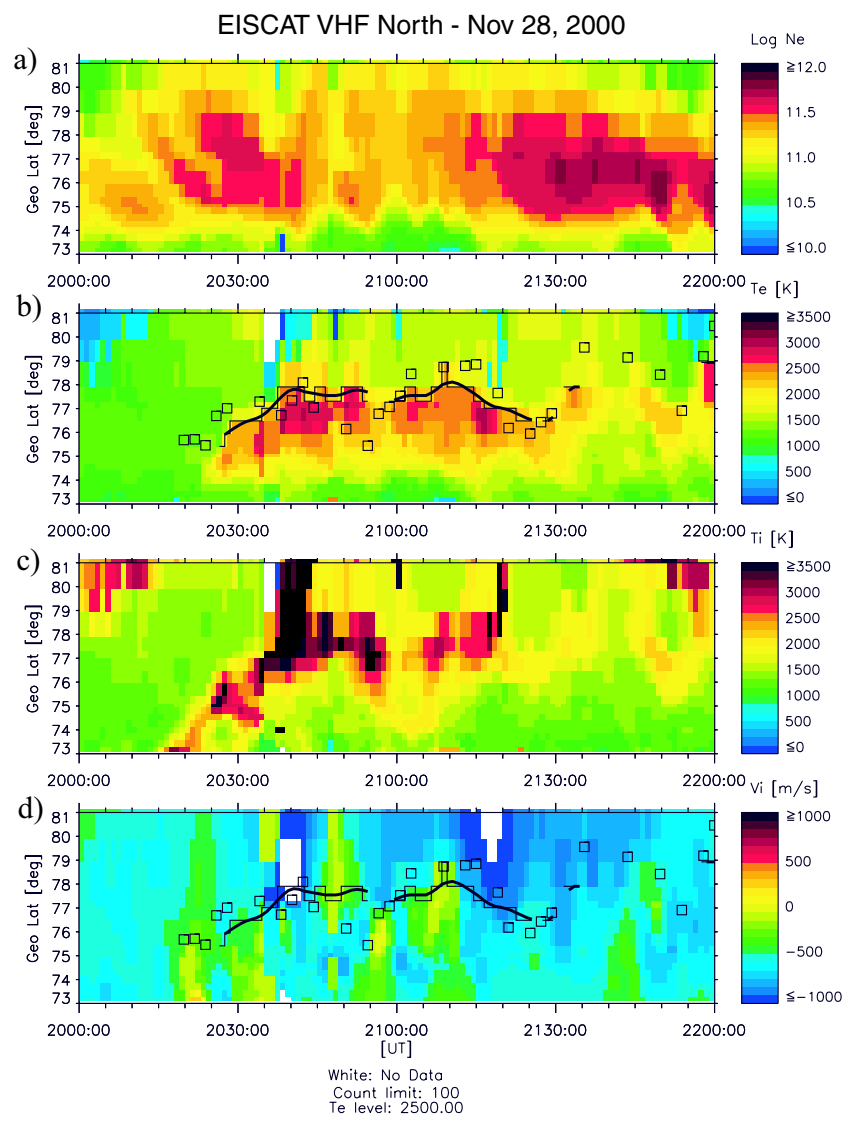

Fig. 5. The measurements along the north beam of the EISCAT VHF radar. The gate positions are mapped along the magnetic field line down to $100 \mathrm{~km}$ altitude. Time resolution is $1 \mathrm{~min}$. The four panels show (a) the electron density, $\mathrm{Ne}$, (b) the electron temperature, $\mathrm{Te},(\mathbf{c})$ the ion temperature, $\mathrm{Ti}$ and (d) the ion velocity, $\mathrm{Vi}$, along the line of sight with positive values to the north. The open closed boundary inferred from the Te measurement is shown by solid lines. The thin line is the actual gate position and the thick line is the same boundary smoothed. The squares show the openclosed boundary inferred from the WIC images.

velocity are shown. The reconnection electric field in the magnetotail and its projection to the ionosphere (Figure 6e and 6d) are then calculated from Eqs. 6 and 7). The magnetic latitude $(\theta)$ dependent dipole field strength (in nT) is used as input in these calculations (Eq. (6).

$B(\theta)=32000 \sqrt{1+3 \sin \theta}$.

The thin lines in panels (c-e) show the results when the velocity in the gate position defining the boundary (thin line in Fig. 5d) is used. The thick lines show the result when the average of this velocity and the velocity in the two gates poleward and equatorward are used. The latter corresponds to the average within $90 \mathrm{~km}$ up to a few hundreds of $\mathrm{km}$. As the two lines are nearly on top of each other we feel confident that any uncertainties regarding the boundary determination should not affect our results significantly. The magnetotail reconnection electric field estimated from the north beam is varying between $1.0 \mathrm{mV} / \mathrm{m}$ and $0 \mathrm{mV} / \mathrm{m}$. The variations are
EISCAT VHF North - Nov 28, 2000
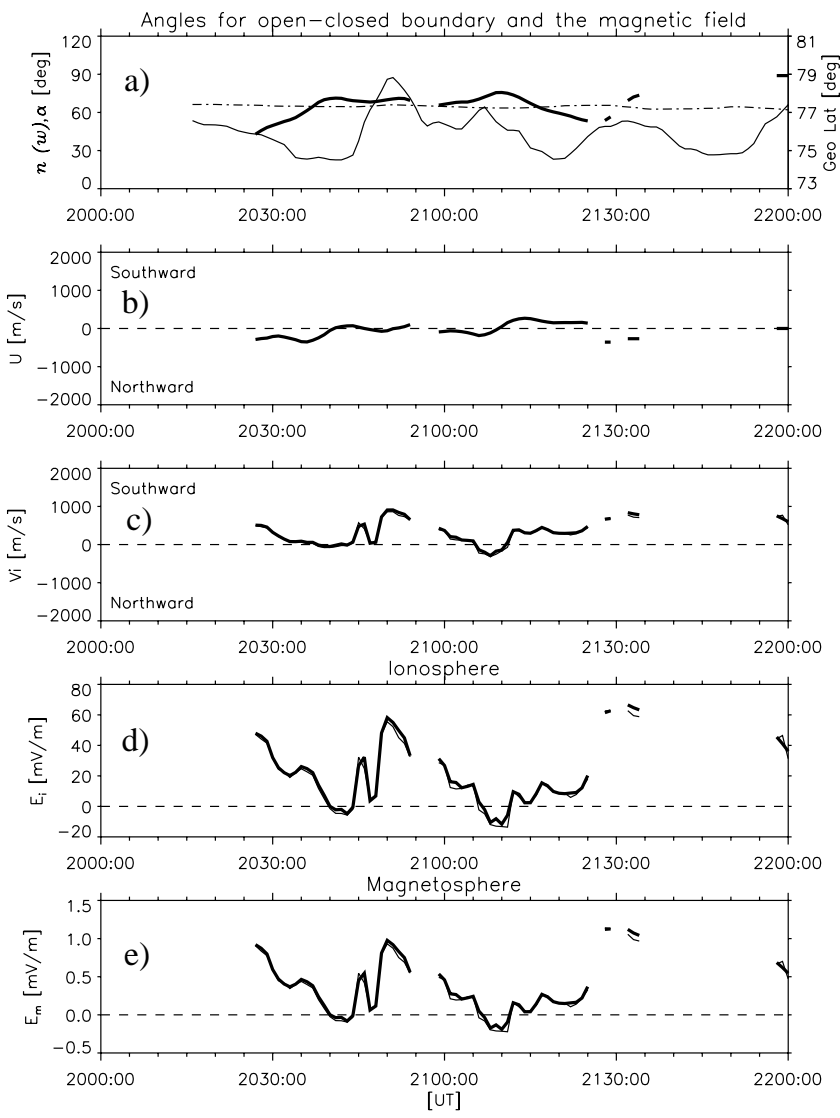

Fig. 6. The reconnection rate estimated from the north beam: (a) Thick line: the smoothed geographic latitude of the open-closed boundary, thin line: the angle, $n$, between the open-closed boundary and the line-of-sight and dashed-dotted line: the angle $\alpha$, between the magnetic field and the line-of-sight. (b) The smoothed boundary velocity, $u$ Eq. (10) (c) Thin line: the maximum ion flow velocity, $v$, Eq. (8) in the gate position defining the open-closed boundary (thin line in Fig. 5d) and thick line: The maximum ion flow velocity when the average of three gate positions are used (d). The ionospheric projection of the reconnection electric field (Eq. (6) using one $v$ value (thin) and the average of three $v$-values (thick). (e) The reconnection electric field in the magnetosphere (Eq. (7).

mostly due to ion flow velocity changes, although small oscillations are seen in the boundary velocity.

In Fig. 7 we show the same parameters estimated from measurements along the west beam. The time and spatial resolution is the same as for the north beam. Along this beam the reconnection rate shows larger variations, which are mostly due to the boundary velocity. We notice that the reconnection rate oscillations have periods of about $15 \mathrm{~min}$.

\section{December 2000}

On 7 December 2000 the Svalbard EISCAT radar provided data from 17:00-22:00 UT, while IMAGE provided the global context as well as boundary characteristics along the 
radar beam direction. After staying close to $0 \mathrm{nT}$ for $3 \mathrm{~h}$, the AE index (Fig. 8b) increased around 17:00 UT, indicating a small substorm around that time, which was confirmed by images (not shown). The AE index peaked at about 18:20 UT $(450 \mathrm{nT})$, then dropped to about $250 \mathrm{nT}$ and stayed between $250 \mathrm{nT}$ and $300 \mathrm{nT}$ for the rest of the interval. The IMAGE WIC images (Fig. 8c) illustrate the overall activity during the times of radar observations.

The first column (18:00-19:00 UT) shows the substorm that started at 17:00 UT. Around 19:00 UT the aurora stays very quiet for almost two hours until a small break-up, which may be classified as a small substorm, occurred around 20:40 UT.

In Fig. 9 the 26-s EISCAT Svalbard radar data are shown. Regarding open-closed boundary determination, an electron temperature of $1800 \mathrm{~K}$ was found to give the best correlation with the boundary determined from the images. For half of the interval (after 19:40 UT) we see that the two data sets give boundary determination within the uncertainties of the image data $\left(100 \mathrm{~km}\right.$ or $\left.1^{\circ}\right)$. During the interval between 18:2018:40 UT the images display bright aurora without showing up as any increase in the electron temperature. In the interval from 19:00 UT to 19:40 UT the electron temperature shows significant increases, giving a clear boundary almost $2^{\circ}$ poleward of the boundary determined from the faint aurora.

The angles, velocities and reconnection rate estimated from these measurements are shown in Fig. 10. Again, to avoid large steps in boundary velocity due the spatial resolution of the radar measurements, we have performed a 2$\min$ (5 data points) boxcar averaging on the boundary and the boundary velocity. In this case, the average ion flow velocity over three intervals (thick line in Fig. 10c) ranges from $90 \mathrm{~km}$ to $180 \mathrm{~km}$. Two distinct bursts of increased reconnection rate are seen, one from 19:00-20:00 UT, when the aurora is almost absent and another from 20:40 UT, when the auroral break-up is seen. The oscillations which are mainly due to the boundary velocity have periods of $\sim 10 \mathrm{~min}$.

During this event, Geotail measured plasma and magnetic field parameters in the plasma sheet at $\mathrm{X}=-15 R_{E} 2-4 \mathrm{~h}$ dawnward of where the EISCAT Svalbard radar measurements were obtained, as illustrated in Fig. 11a. Both the density, temperature and magnetic field measurements indicate that Geotail was in the plasma sheet. Strong bursty bulk flows (BBF) were observed prior to 19:00 UT (Fig. 11d and f), which coincided with auroral activity, but were not associated with any reconnection signatures in the radar data. As such, BBFs are usually observed in a narrow channel in the plasma sheet (Angelopoulos et al., 1992) and the EISCAT Svalbard radar, at this point, might have been measuring on field lines that map to the duskward flank of the magnetosphere, i.e. outside the region of BBFs. After 19:00 UT Geotail moves dawnward, but oscillations on the time scale of 10-15 min can still be seen in the duskward electric field (as derived from $V_{x}$ times $B_{z}$ in Fig. 11f) in the interval 19:0020:00 UT and around 21:00 UT, with a relatively quiet interval in between. Although there is not a one-to-one correlation, the oscillations are in the same range $(0-1 \mathrm{mV} / \mathrm{m})$
EISCAT VHF West - Nov 28, 2000
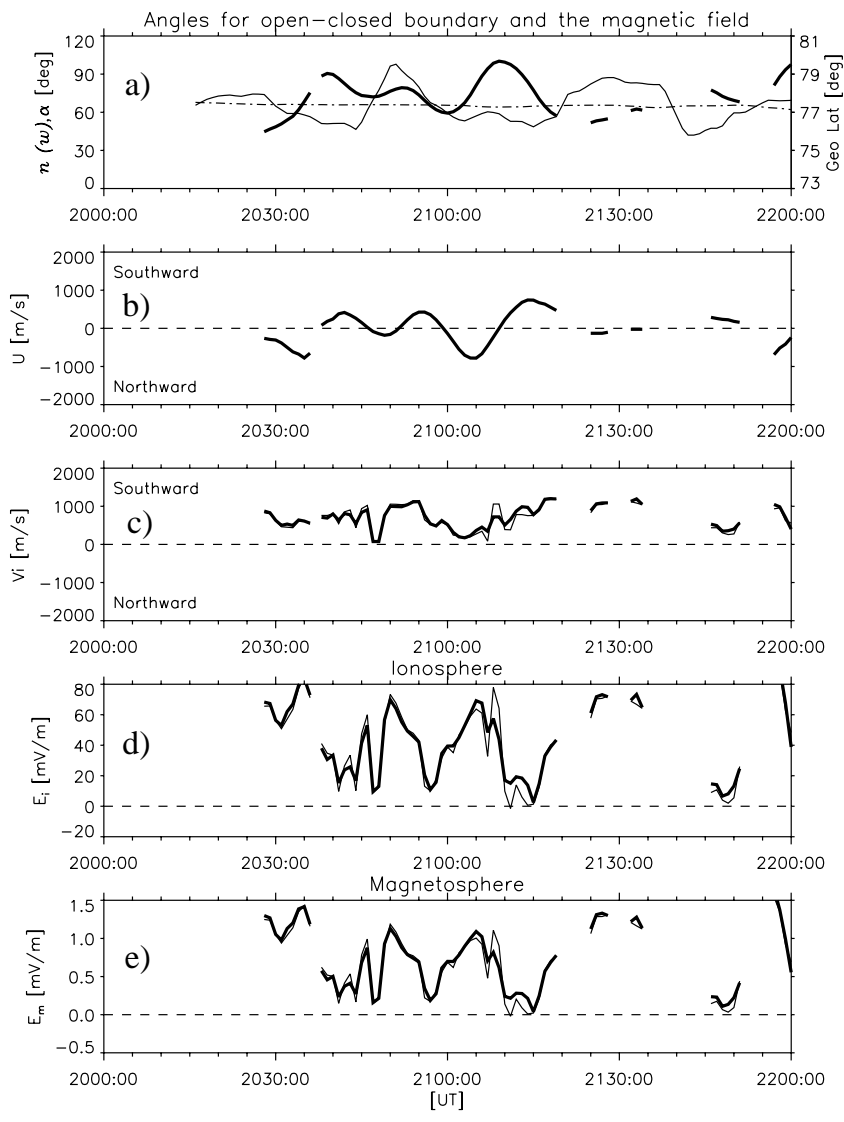

Fig. 7. Same as Fig. 6, but for the west beam.

and on the same time scale as the radar observations reveal (Fig. 11g). This indicates that these oscillations are not localized but extend through large parts of the nightside magnetosphere.

\section{Discussion}

The most crucial parameter in our estimate of the magnetotail reconnection electric field is the determination of the openclosed boundary.

Blanchard et al. (1996) used the electron density in the E-layer $\left(3 \cdot 10^{10} \mathrm{~m}^{-3}\right)$ combined with latitudinal scans of $630.0 \mathrm{~nm}$ emissions and found a rms difference between the two methods of $\pm 0.6^{\circ}$.

Ober et al. (2001) used the $130.4 \mathrm{~nm}$ images from the Polar VIS Earth camera. Due to resonance scattering of this emission it may be argued that the images will be smeared out somewhat and is not so good for determining accurate boundary location.

In this study we have used global imaging data from the IMAGE FUV instruments and the electron temperature from the EISCAT radar measurements to estimate the open-closed boundary. The discrepancies between the two boundary determinations are, for most of the time, in the range of the 

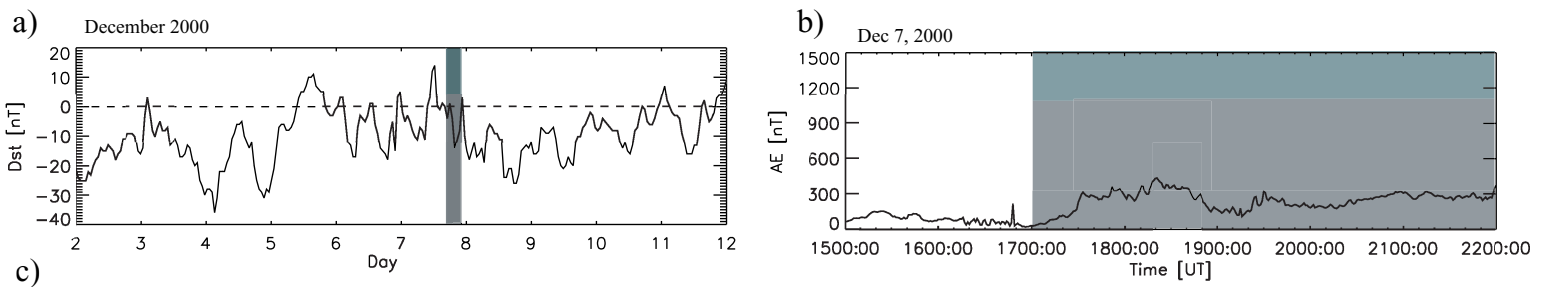

c)
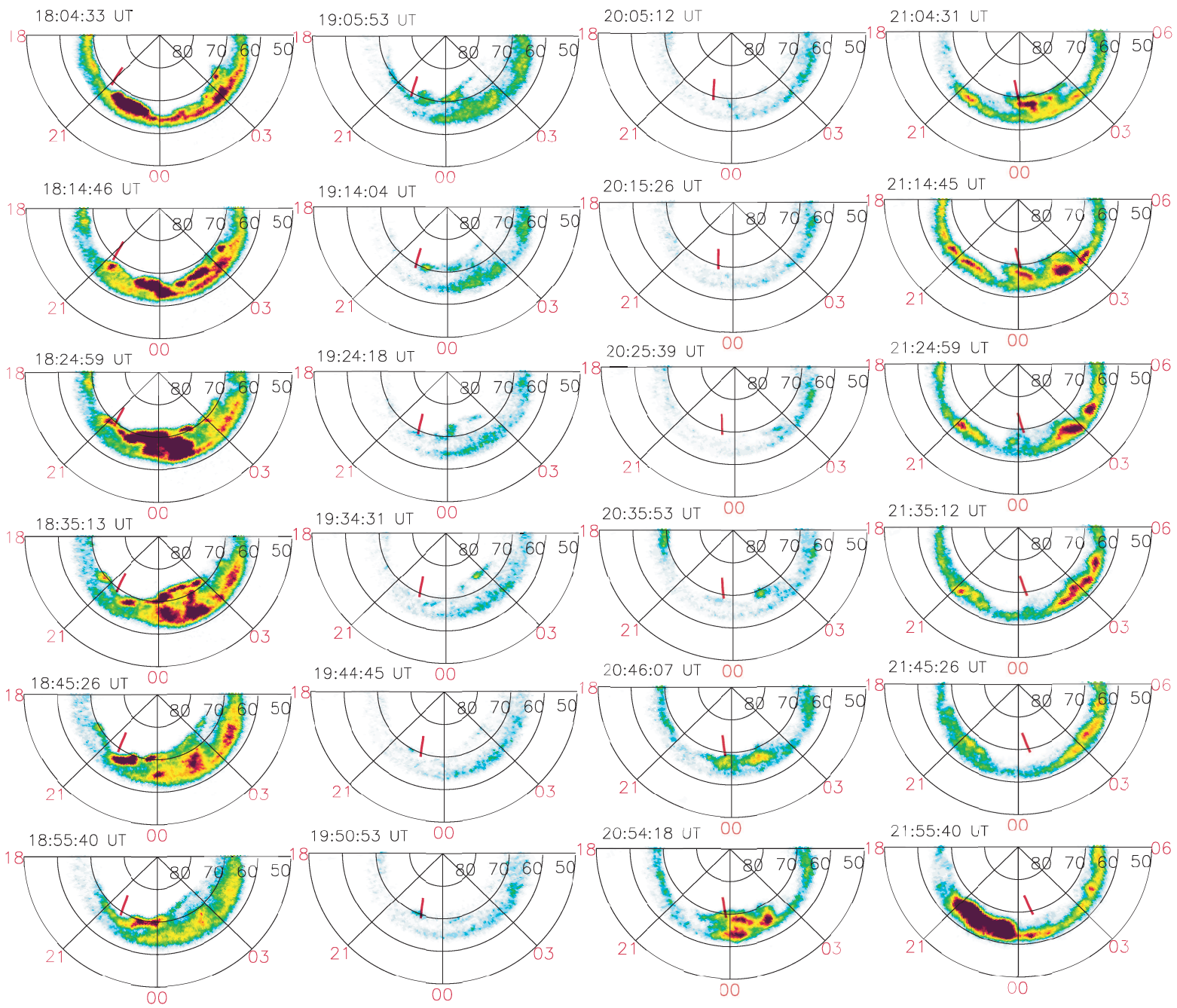

Fig. 8. (a) $D_{s t}$ and (b) $A E$ indices during the observations on 7 December 2000. (c) IMAGE/ FUV WIC images from 18:00-22:00 UT. The EISCAT Svalbard radar beam is marked with a red line.

spatial resolution of the images. We have shown that the average of the ion flow velocity in three adjacent spatial intervals give the same result as using the ion flow in the exact boundary interval. The spatial averaging applied to the ion velocity ranges from $90-180 \mathrm{~km}$. This means that any error in our boundary determination less than $\sim 100 \mathrm{~km}$ should not affect our result significantly. However, there are some intervals when the two techniques give discrepancies larger than the spatial resolution of the images, indicating that the openclosed boundary determination during these times is more uncertain.
Although Blanchard et al. (1996) used all-sky cameras to check the assumption of a boundary orientation parallel to the L-shell at Søndre Strømfjord, they did not have continuous information of the boundary orientation as provided by IMAGE FUV during our observations.

In order to calculate the boundary velocity, we have assumed that the boundary motion is along the magnetic meridian. Although this is partly supported by the images, it may not always be true and represents a source of error in our estimate. This means that variations in the reconnection rate caused by the boundary velocity could sometimes have larger or smaller amplitudes. However, the 5 data-point smoothing 

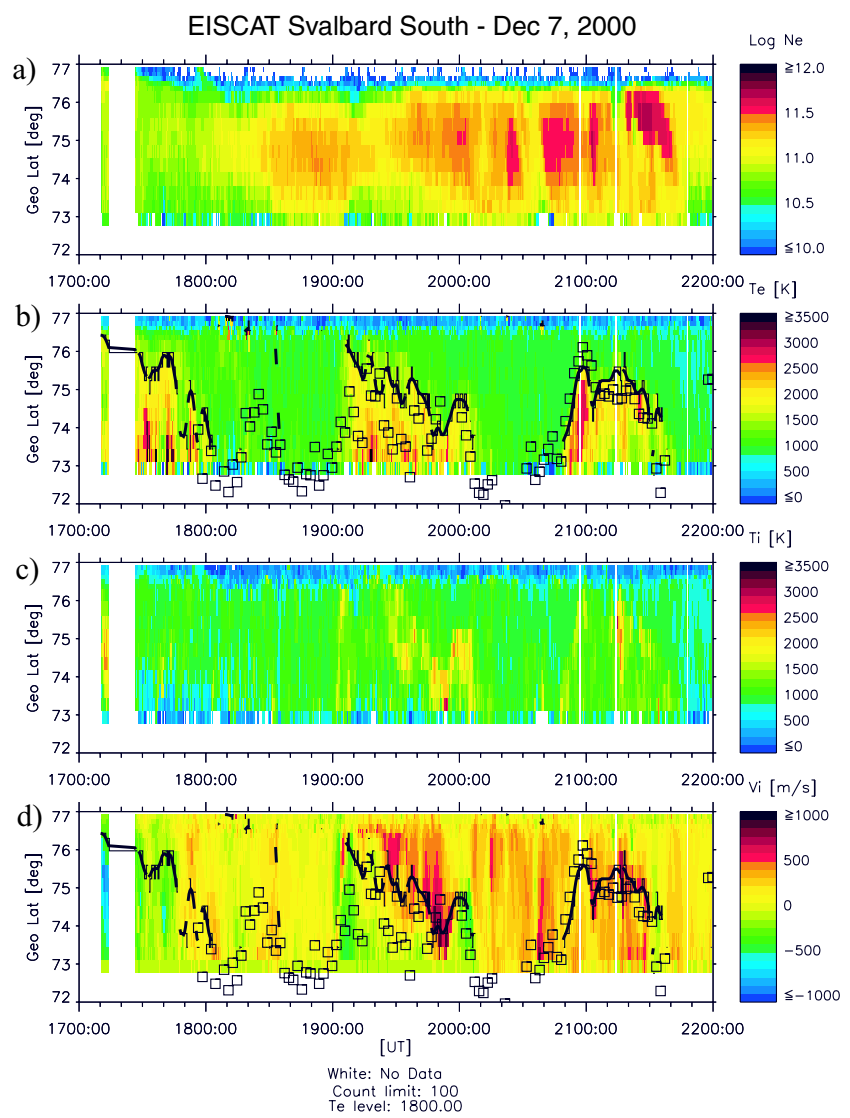

Fig. 9. Same as Fig. 5, but for the EISCAT Svalbard radar on 7 December 2000. Time resolution is $26 \mathrm{~s}$.

of the boundary location we have performed to avoid large steps in velocity is in fact a way of filtering out large oscillations, which may indicate that we rather underestimate than overestimate these oscillations. To summarize, by properly taking into account the geometry of the observations as well as the uncertainties of our boundary determination, we argue that our estimates should reflect fairly well the real reconnection electric field in the magnetotail.

We find the magnitude of the magnetotail reconnection electric field to be between $0 \mathrm{mV} / \mathrm{m}$ and $1 \mathrm{mV} / \mathrm{m}$ (or 0 $80 \mathrm{mV} / \mathrm{m}$ in the ionospheric projection), which is in good agreement with earlier results (Blanchard et al., 1996; Ober et al., 2001). It is also in the same range as the Geotail in-situ measurements of the electric field earthward of the reconnection site in the magnetotail.

During the observations on 7 December 2000, between 19:00 UT and 20:00 UT, increased reconnection electric field is seen in the ESR data, without showing any significant auroral intensity increase in the WIC images. However, we do see auroral activity associated with the BBFs observed by Geotail prior to 19:00 UT, consistent with earlier studies (Fairfield et al., 1999; Nakamaura et al., 2001).

Blanchard et al. (1996) estimated a coupling efficiency between the solar wind and the magnetotail reconnection electric field to be 0.1 , which is similar to what has been assumed
EISCAT Svalbard South - Dec 7, 2000
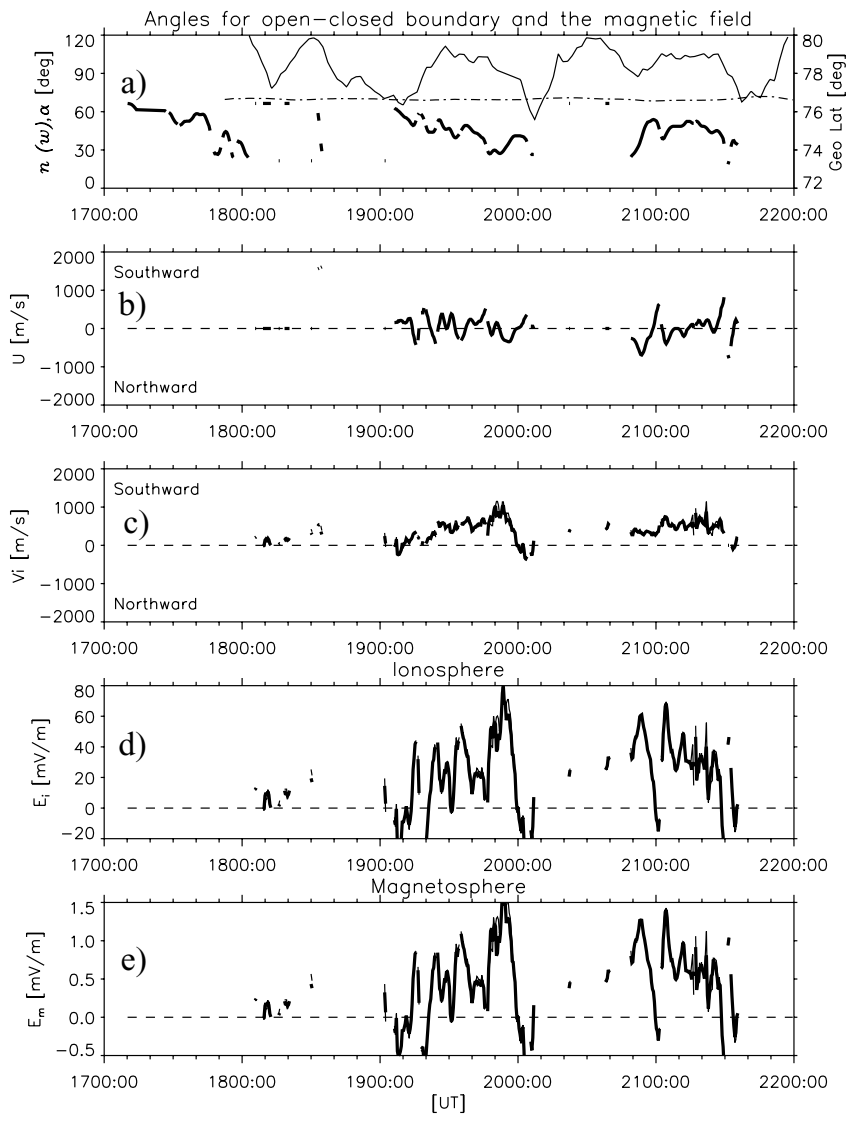

Fig. 10. Same as Fig. 6, but for the South beam. Eq. 9 is used to estimate the maximum ion velocity perpendicular to the boundary and magnetic field.

by some modelers (e.g. Horton and Doxas, 1996). Blanchard et al. (1996) also reported a peak correlation lagging the solar wind electric field by about $70 \mathrm{~min}$. As Fig. 12 illustrates, we do not find any significant correlation between the solar wind electric field and the magnetotail reconnection rate. Cross correlation peaks around 0.4 with different time lags. We do find an average coupling efficiency for 28 November 2000 to be in the same range as reported previously. However, for 7 December 2000 we obtain an efficiency coefficient of 0.8 , mostly due to the very weak solar wind electric field. The absence of correlation and these highly variable efficiency values indicate that magnetotail reconnection is not directly driven but is an internal magnetospheric process. The term "coupling efficiency" between the solar electric field and the reconnection electric field is probably only valid as average over long time intervals.

Large oscillations with periods of $10-15 \mathrm{~min}$ are seen during both events. These are caused mainly by the motion of the open-closed boundary, although the ion flow velocity may also oscillate (north beam, 28 November). Our results indicate that magnetotail reconnection is not a steady process, but a bursty oscillating process. For one of the events Geotail measured similar electric field oscillations in 
a)

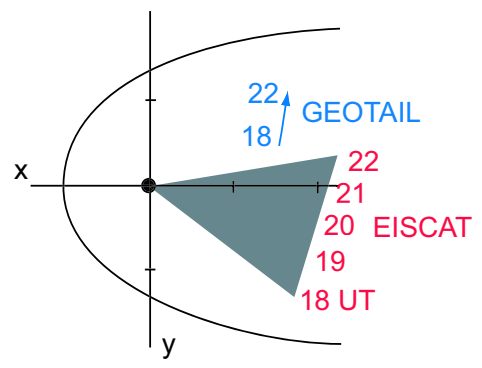

b)

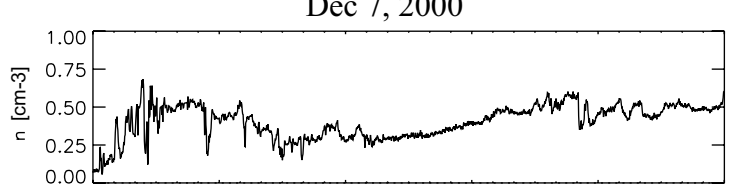

c)
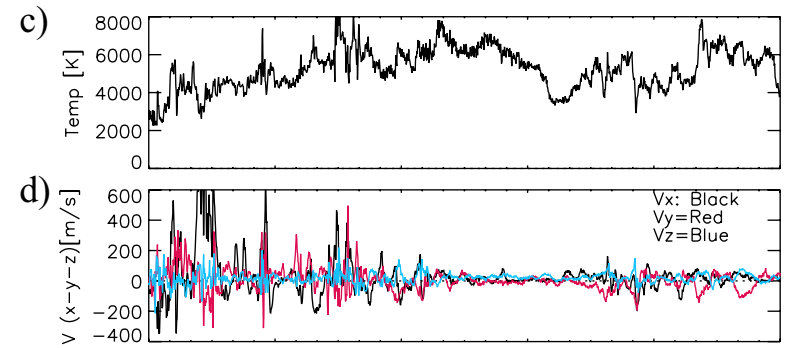

e)

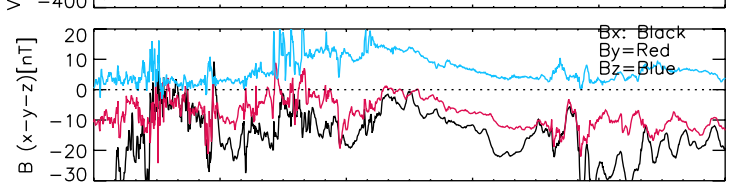

f)

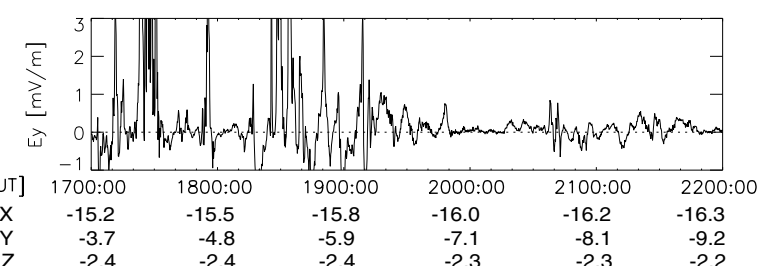

g)

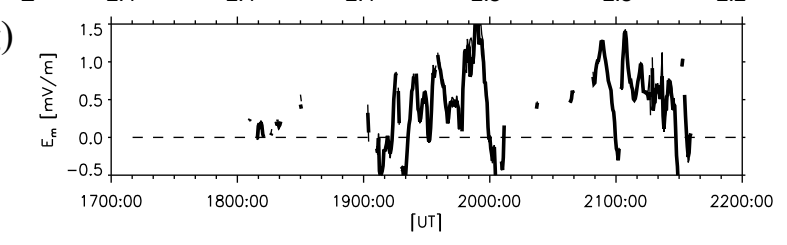

Fig. 11. (a) The Geotail trajectory and the sector the ESR data are obtained. (a-g) Geotail measurements in the nightside plasma sheet. (b) density, (c) temperature, (d) the three components of the ion bulk velocity, (e) the three magnetic field components, (f) the duskward electric field $\left(\mathrm{V}_{\mathrm{X}} \cdot \mathrm{B}_{\mathrm{Z}}\right)$ and $(\mathrm{g})$ the reconnection rate estimated from the radar measurements.

the plasma sheet earthward of the reconnection site. These in-situ measurements both confirm the radar observations and indicate that ULF oscillations extend through large parts of the magnetosphere. ULF oscillations with a typical period of 10-15 min have been reported for polar boundary intensifications (PBIs) associated with BBFs (Lyons et al., 2002) and during substorms simultaneously in the magnetotail, at geosynchronous orbits and on ground (Sánchez et al., 1997; Mishin et al., 2002). While some claim that these oscillations are field line resonances with frequencies compatible with
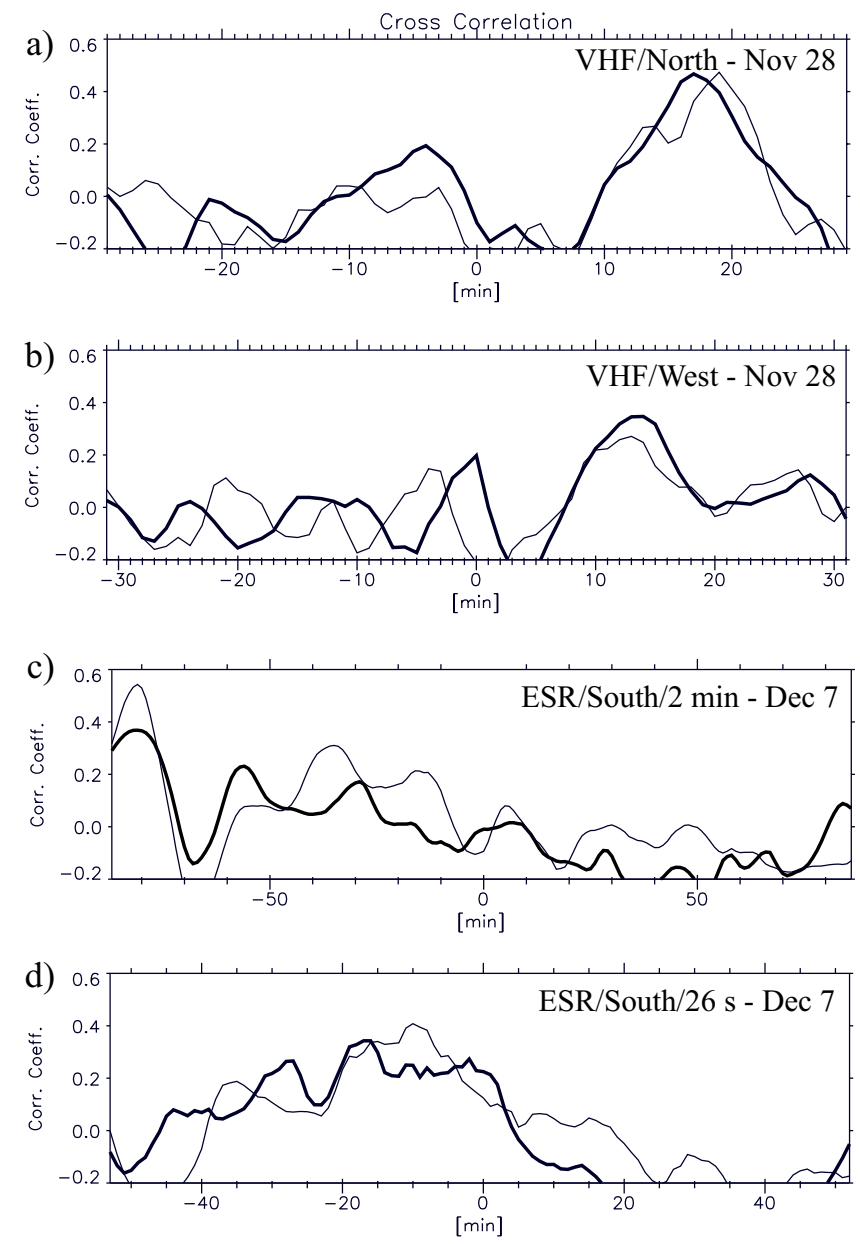

Fig. 12. Cross correlation with the solar wind electric field for the 4 data sets, using ACE data (thick line) and Wind data (thin line). Solar wind data are time shifted to the sub solar magnetosphere $\left(\mathrm{X}=10 R_{E}\right)$.

global cavity modes associated with substorm activity (Samson et al., 1992; Sánchez et al., 1997), others have suggested that they are externally driven by solar wind pressure (Kepko and Spence, 2003) and/or IMF changes (Mishin et al., 2002).

Figure 13 displays the power frequency spectra of the solar wind pressure, the duskward electric field measured by Geotail and the reconnection electric field from the ESR data. Although the signal is fairly weak, the Wind measurements show a distinct peak at $0.5 \mathrm{mHz}$ in agreement with Kepko and Spence (2003). In addition to the peak at $1.0 \mathrm{mHz}$ the electric fields measured by Geotail and ESR both show peaks at lower frequencies, 0.5 and $0.8 \mathrm{mHz}$. As these frequencies are below the lower limit $(\sim 1 \mathrm{mHz})$ that can be related to cavity modes and internal wave speed (Kepko and Spence, 2003), these results lend support to the possibility that the solar wind pressure can be the driver of these oscillations. To summarize, we find no strong connection between the solar wind electric field and the reconnection rate in the magnetotail. This leads us to believe that magnetotail reconnection is an internal magnetospheric process. On the other hand, based 


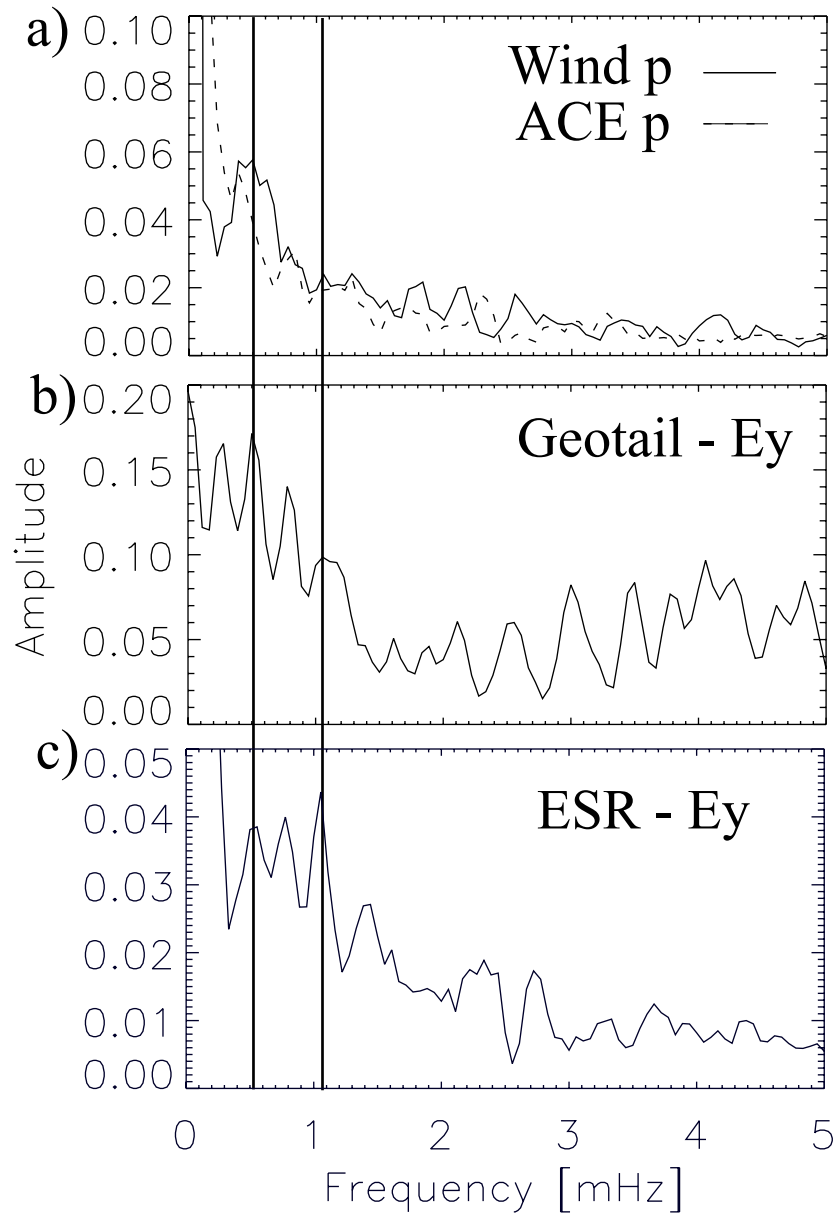

Fig. 13. Average power spectrum over the time interval 17:0022:00 UT, 7 December 2000, of (a) the solar wind pressure, (b) duskward electric field measured by Geotail and (c) reconnection electric field measured by ESR. Vertical lines mark the cavity mode at $1 \mathrm{mHz}$ and the solar wind pressure variations at $0.5 \mathrm{mHz}$.

on the power spectra we cannot rule out that the solar wind pressure may modulate the process and impose oscillations modes at low frequencies, in addition to internal magnetospheric modes.

\section{Conclusion}

In this paper we have reported how the ion flow across the open-closed boundary can be used to estimate the reconnection electric field in the magnetotail. When guided and confirmed by global imaging by IMAGE FUV we have shown that the electron temperature measurements by the incoherent-scatter EISCAT radars can be used to identify the open-closed boundary. Determination of the orientation of the boundary was based on global imaging by IMAGE FUV. During the two days of observations from the EISCAT radars in Troms $\varnothing$ and on Svalbard we have found:

1) The magnetotail reconnection electric field is not steady but oscillates with a period of $10-15 \mathrm{~min}$ between $0 \mathrm{mV} / \mathrm{m}$ and $1 \mathrm{mV} / \mathrm{m}$. The ULF oscillations, which have been found to be a characteristic oscillation mode of the magnetosphere, are mainly due to the motion of the open-closed boundary. Simultaneous in-situ measurements indicate that these oscillations extend through large parts of the magnetosphere.

2) Bursts of increased magnetotail reconnection electric field do not necessarily have any auroral signature.

3) The reconnection rate shows poor correlation with the solar wind electric field. This indicates that the magnetotail reconnection is not a directly driven process, but an internal magnetospheric process. Estimates of a coupling efficiency between the solar wind electric field and magnetotail reconnection give no consistent results and only seem to be relevant when averaged over long time intervals. Power spectra indicate that the solar wind pressure may modulate this process by imposing oscillations modes, in addition to internal modes.

Acknowledgements. We want to thank T. Phan for useful discussions and S. Frey for performing the field line mapping of the EISCAT radar beam locations. The IMAGE FUV investigations were supported by NASA through SwRI subcontract number 83820 at the University of California at Berkeley under contract number NAS5-96020. EISCAT is an international association supported by Finland (SA), France (CNRS), Germany (MPG), Japan (NIPR), Norway (NFR), Sweden (NFR), and the United Kingdom (PPARC). J. Moen and K. Oksavik are supported by the Norwegian Research Council and AFOSR task 2311AS. We acknowledge the World Data Center for Geomagnetism (T. Kamei), Kyoto, Japan for providing the preliminary Quick look $A E, A L$ and $A U$ indices and provisional Dst index. Solar wind data were obtained from the CDAweb. We acknowledge the following PIs: Wind Magnetic Field Investigations, R. Lepping; Wind Solar Wind Experiment, K. Ogilvie; ACE/SWEPAM Solar Wind Experiment, D. J. McComas and CE Magnetic Field Instrument, N. Ness.

Topical Editor T. Pulkkinen thanks L. Lyons and another refereee for their help in evaluating this paper.

\section{References}

Angelopoulos, V., Baumjohann, W., Kennel, C. F., Coroniti, F. V., Kivelson, M. G., Pellat, R., Walker, R. J., Lühr, H., and Paschmann, G.: Bursty bulk flows in the inner central plasma sheet, J. Geophys. Res., 97, 4027-4039, 1992.

Blanchard, G. T., Lyons, L. R., de la Beaujardiére, O., Doc, R. A., and Mendillo, M.: Measurements of the magnetotail reconnection rate, J. Geophys. Res., 101, 15 265-15 276, 1996.

Blanchard, G. T., Lyons, L. R., and de la Beaujardiére, O.: Magnetotail reconnection rate during magnetospheric substorms, J. Geophys. Res., 102, 24 303-24 312, 1997.

de la Beaujardiére, O., Lyons, L. R., and Friis-Christensen, E.: Sondrestrom radar measurements of the reconnection electric field, J. Geophys. Res., 96, 13 907-13 912, 1991.

Doe, R. A., Vickrey, J. F., Weber, E. J., Gallagher, H. A., and Mende, S. B.: Ground-based signatures for the nightside polar cap boundary, J. Geophys. Res., 102, 19 989-20 005, 1997.

Dungey, J. W.: Interplanetary magnetic field and the auroral zones, Phys. Rev. Lett., 6, 47-48, 1961. 
Fairfield, D. H., Mukai, T., Brittnacher, M., Reeves, G. D., Kokubun, S., Parks, G. K., Nagai, T., Matsumoto, H., Hashimoto, K., Gurnett, D. A., and Yamamoto, T.: Earthward flow bursts in the inner magnetotail and their relation to auroral brightening, AKR intensifications, geosynchrono us particle injections and magnetic activity, J. Geophys. Res., 104, 355-370, 1999.

Frey, H. U., Mende, S. B., Immel, T. J., Gérard, J. C., Hubert, B., Spann, J., Gladstone, G. R., Bisikalo, D. V., and Shematovich, V. I.: Summary of quantitative interpretation of IMAGE ultraviolet auroral data, Space Sci. Rev., 109, 255-283, 2003.

Fujii, R., Hoffman, R. A., Anderson, P. C., Craven, J. D., Sugiura, M., Frank, L. A., and Maynard, N. C.: Electrodynamic parameters in the nighttime sector during auroral substorms, J. Geophys. Res., 99, 6187-6199, 1994.

Hesse, M., Schindler, K., Birn, J., and Kuznetsova, M.: The diffusion region in collisionless magnetic reconnection, Phys. Plasma, 6, 1781, 1999.

Hoffman, R. A., Fujii, R., and Sugiura, M.: Characteristics of the field-aligned current system in the nighttime sector during auroral substorms, J. Geophys. Res., 21, 21 303-21 326, 1994.

Horton, W. and Doxas, I.: A low-dimension energy-conserving state space model for substorm dynamics, J. Geophys. Res., 101, 27 223-27 237, 1996.

Kagan, L. M., Kelley, M. C., and Doe, R. A.: Ionosphereic electron heating by structured electric fields: Theory and experiment, J. Geophys. Res., 101, 10 893-10 907, 1996.

Kelley, M. C.: The Earth's Ionosphere Plasma Physics and Electrodynamics, Academic Press, Inc., San Diego, 1989.

Kepko, L. and Spence, H. E.: Observations of discrete, global magnetospheric oscillations directly driven by solar wind density variations, J. Geophys. Res., 108, 1257, 2003.

Lockwood, M.: Identifying the open-closed field line boundary, in Polar cap boundary phenomena, edited by J. Moen, A. Egeland, and M. Lockwood, pp. 73-90, Kluwer Academic Publishers in cooperation with NATO Scientific Affairs Division, Dordrecht, Boston, London, 1997.

Lyons, L., Zesta, E., Xu, Y., Sánchez, E. R., Samson, J. C., Reeves, G. D., Ruohoniemi, J. M., and Sigwarth, J. B.: Auroral poleward boundary intensifications and tail bursty flows: A manifestation of a large-scale ULF oscillation?, J. Geophys. Res., 107, 1352, 2002.
Mende, S. B., Heetderks, H., Frey, H. U., Lampton, M., Geller, S. P., Abiad, R., Siegmund, O. H. W., Tremsin, A. S., Spann, J., Dougani, H., Fusilier, S. A., Magoncelli, A. L., Bumala, M. B., Murphree, S., and Trondsen, T.: Far ultraviolet imaging from the IMAGE spacecraft. 2. Wideband FUV imaging, Space Sci. Rev., 91, 271-285, 2000.

Mishin, E. V., Foster, J. C., Potekhin, A. P., Rich, F. J., Schlegel, K., Yumoto, K., Taran, V. I., Ruohoniemi, J. M., and Friedel, R.: Global ULF disturbances during a stormtime substorm on 25 September 1998, J. Geophys. Res., 107, 1486, 2002.

Nakamaura, R., Baumjohan, W., Sergeev, M. B. V., Kubyshkina, M., Mukai, T., and Liou, K.: Flow burst and auroral activations: Onset timing and foot point location, J. Geophys. Res. 106, 10777 (2000JA000 249), 2001.

Ober, D. M., Maynard, N. C., Burke, W. J., Peterson, W. K., Sigwarth, J. B., Frank, L. A., Scudder, J. D., Hughes, W. J., and Russell, C. T.: Electrodynamics of the poleward auroral border observed by Polar during a substorm on April 22, 1998, J. Geophys. Res., 106, 5927-5943, 2001.

Pedersen, A., Catelli, C. A., Fälthammar, C. G., Knott, K., Lindqvist, P. A., Manka, R. H., and Mozer, F. S.: Electric fields in the plasma sheet and plasma sheet boundary, J. Geophys. Res., 90, 1231, 1985.

Russell, C. T.: The configuration of the magnetosphere, in Critical Problems of Magnetospheric Physics, edited by E. R. Dyer, pp. 1-16, National Academy of Sciences, Washington D.C., 1972.

Samson, J. C., Lyons, L. R., Newell, P. T., Creutzberg, F., and Xu, B.: Proton aurora and substorm intensifications, Geophys. Res. Lett., 19, 2167-2170, 1992.

Sánchez, E. R., Kelly, J. D., Angelopoulos, V., Hughes, T., and Singer, H.: Alvén modluation of the substorm magnetotail transport, Geophys. Res. Lett., 24, 979-982, 1997.

Tsyganenko, N. A.: A model of the near magnetosphere with a dawn-dusk asymmetry 1. Mathematical structure, J. Geophys. Res., 107, 1179, 2002.

Vasyliunas, V. M.: Steady state aspects of magnetic field line merging, in Magnetic Reconnection in Space and Laboratory Plasmas, Geophys. Monogr. Ser., vol. 30, edited by E. W. Hones, Jr., pp. 25-31, AGU, Washington, D. C., 1984.

Yamade, Y., Fujimoto, M., Yokokawa, N., and Nakamura, M. S.: Field-aligned currents generated in magnetotail reconnection, Geophys. Res. Lett., 27, 1091, 2000. 